University of Massachusetts Amherst

ScholarWorks@UMass Amherst

Chemistry Department Faculty Publication Series

Chemistry

1990

\title{
A Study of Laser Ablation and Slurry Nebulisation Sample Introduction for the Analysis of Geochemical Materials by Inductively Coupled Plasma Spectrometry
}

Julian Tyson

University of Massachusetts Amherst

S. A. Darke

S. E. Long

C. J. Pickford

Follow this and additional works at: https://scholarworks.umass.edu/chem_faculty_pubs

Part of the Chemistry Commons

\section{Recommended Citation}

Tyson, Julian; Darke, S. A.; Long, S. E.; and Pickford, C. J., "A Study of Laser Ablation and Slurry Nebulisation Sample Introduction for the Analysis of Geochemical Materials by Inductively Coupled Plasma Spectrometry" (1990). Fresenius Journal of Analytical Chemistry. 1304.

Retrieved from https://scholarworks.umass.edu/chem_faculty_pubs/1304

This Article is brought to you for free and open access by the Chemistry at ScholarWorks@UMass Amherst. It has been accepted for inclusion in Chemistry Department Faculty Publication Series by an authorized administrator of ScholarWorks@UMass Amherst. For more information, please contact scholarworks@library.umass.edu. 


\title{
A study of laser ablation and slurry nebulisation sample introduction for the analysis of geochemical materials by inductively coupled plasma spectrometry*
}

\author{
S. A. Darke ${ }^{1+}$, S. E. Long ${ }^{1 *}$, C. J. Pickford ${ }^{1}$, and J. F. Tyson ${ }^{2+}$ \\ ${ }^{1}$ Environmental and Medical Sciences Division, Harwell Laboratory, Oxfordshire, OX11 ORA, UK \\ ${ }^{2}$ Department of Chemistry, University of Technology, Loughborough, Leics., LE11 3TU, UK
}

\begin{abstract}
Summary. The performances of two alternative sample introduction methods for use with Inductively Coupled Plasma-Optical Emission Spectroscopy (ICP-OES) and Inductively Coupled Plasma-Mass Spectrometry (ICP-MS) have been evaluated for the analysis of the same sample material. The laser ablation sample introduction system is based on a Nd:YAG laser to which an $\mathrm{x}-\mathrm{y}-\mathrm{z}$ translational sampling head had been added. A study has been made of a number of parameters which affect the performance of the system to find the optimum operating conditions. The slurry introduction system involved aspirating the slurries into the plasma using a "de Galan" nebuliser and a "Scott-type" spray chamber arrangement. A study has been made of the parameters which control the production of stable homogeneous slurries. Initial particle size measurements have been carried out on the slurried samples to show how this affects this method of sample introduction. Results are presented for the analysis of a South African reference material rock sample (SARM 5) by ICP-OES with both laser ablation and slurry nebulisation sample introduction and some preliminary results for the analysis by ICP-MS with laser ablation introduction. Semi-quantitative results are obtained for laser ablation ICP-OES as only one matrix matched standard is used. However, the agreement between the results obtained for slurry nebulisation and the certificate value is poor. It is suggested by comparison with previous studies that this may be due to particle size effects. Encouraging results were obtained for the determination of trace elements by laser ablation ICP-MS.
\end{abstract}

\section{Introduction}

Solution nebulisation is the most commonly used method of sample introduction into an ICP system for the analysis

\footnotetext{
* Current address: Technology Applications, US Environmental Protection Agency, Cincinnati, Ohio, USA

Offprint requests to: J. F. Tyson

+ Current address: Department of Chemistry, Lederle Graduate Research Center, University of Massachusetts, Amherst, MA 01003, USA
}

of liquids and solid samples converted to solutions. This process of dissolution may lead to certain problems including a risk of contamination, the risk of losses of volatile elements, dilution of the analyte below the level that can be readily measured and it can greatly increase the analysis time. Some common types of sample may suffer from these disadvantages when introduced into the ICP as solutions. Solid sample introduction methods make attractive alternatives in these areas.

Solid sampling methods for ICP have been extensively reviewed [1, 2], although none of these methods has been developed to the extent that they are in widespread routine use. Two such solid sample introduction methods have been investigated in this work for the introduction of geochemical samples into the ICP, namely laser ablation and slurry nebulisation.

The use of a laser for vaporising a solid sample prior to excitation by the ICP was first used by Abercrombie et al. [3] for the analysis of airborne particles by atomic emission spectroscopy (AES). This method of sample introduction has been used by other workers for a range of materials including metals [4], geochemical samples [5], ceramics [6] and glasses [7]. The ablated material produced by the laser interacting with the solid sample is transported by a stream of argon gas to the ICP where it can be analysed by AES [8-10] or MS [11,12].

Slurry nebulisation involves sample introduction of suspensions of finely powdered materials using nebulisers that can tolerate high solid content [13-15]. It offers an advantage over other forms of solid sample introduction viz. the potential for calibration using aqueous standards. Particle size of the suspended material has been found to be an important parameter when using such standards $[16,17]$. Sample types that have been introduced into the ICP using slurry nebulisation include airborne particulate matter [18], clay suspensions [19, 20], soils [21] and silicate rocks [20]. These suspensions were analysed using AES but recent work has involved slurry sample introduction into the ICP for analysis by MS [22, 23]. The second of these recent publications illustrates some of the problems. The study concerned the analysis of some standard reference coals. Six different coals were analysed for major, minor and trace constituents in both semi-quantitative and full quantitative 
modes. In the full quantitative mode, agreement between the result reported and the certificate range was obtained on a total of 30 times out of a possible 104 with recoveries ranging from $35,000 \%$ (for Cd in NBS 1635, certificate value $0.03 \mu \mathrm{g} \mathrm{g}^{-1}$ ) to $9 \%$ (for $\mathrm{Al}$ in SARM 19, certificate value $42,903 \mu \mathrm{g} \mathrm{g}^{-1}$ ). These results were described by the authors as giving "excellent agreement with the certified reference material for a large number of elemental constituents".

The work reported in this paper forms part of a continuing investigation of the relative merits of various solid sampling techniques for ICP. The aim of the study is to develop methods for use with existing instrumentation already installed in the Harwell laboratory for several years and which is used extensively for solution analysis. The laser ablation system therefore had to be portable and easily connected/disconnected. The introduction of slurries had to be made with minimum changes to the basic operating conditions of the instruments. The only changes permitted in practice being the use of alternative nebulisers and/or injector tubes. It was not possible to make substantial changes to power, observation height etc. One goal of the work is to overcome some of the major problems associated with solid sample introduction techniques [24], namely the difficulty of calibration and obtaining homogeneous and representative samples.

In this paper the performance of a laser ablation system and a slurry introduction system for use with ICP-OES and ICP-MS have been evaluated. Studies have been made of a number of parameters which affect the performance of both systems and semi-quantitative results obtained for the analysis of some geochemical reference materials.

\section{Experimental}

\section{Apparatus}

Laser ablation system. The laser used in the laser ablation system was a Spectron Laser Systems (Rugby, Warwicks., UK) Nd:YAG laser, model SL402. It was a free-running laser with a fixed pulse length of $200 \mu$ s and could be operated in two different energy ranges, i.e. the "multimode" $(1.0 \mathrm{~J}-2.0 \mathrm{~J})$ and the "single transverse mode" (TEMoo) $(0.1 \mathrm{~J}-0.2 \mathrm{~J})$. The energy selected depended on the physical properties of the material being ablated. The sample could be moved in three dimensions with respect to the focussed laser beam using an $\mathrm{x}-\mathrm{y}-\mathrm{z}$ translational sampling head. The position of focus was accurately located by an IR (infra-red) beam and detector.

The ablation chamber is shown in Fig. 1. It consisted of a cylindrical glass tube of $35 \mathrm{~mm}$ internal diameter and $80 \mathrm{~mm}$ height, with tangential arms for argon inlet and outlet. The base was made of PTFE, and was constructed with an O-ring seal to allow easy removal for sample change-over. The plate glass cover was angled at $45^{\circ}$ to eliminate reflections within the objective lens. The entire sampling head assembly was enclosed in a steel box with an interlocking door to prevent emission of reflected laser energy into the laboratory. Illumination of the sample was provided by fibre optic light guides.

Slurry nebulisation. The slurries were introduced into the ICP torch using a de Galan V-groove high solids nebuliser (Van der Plas Products, Voorschoten, The Netherlands) to-

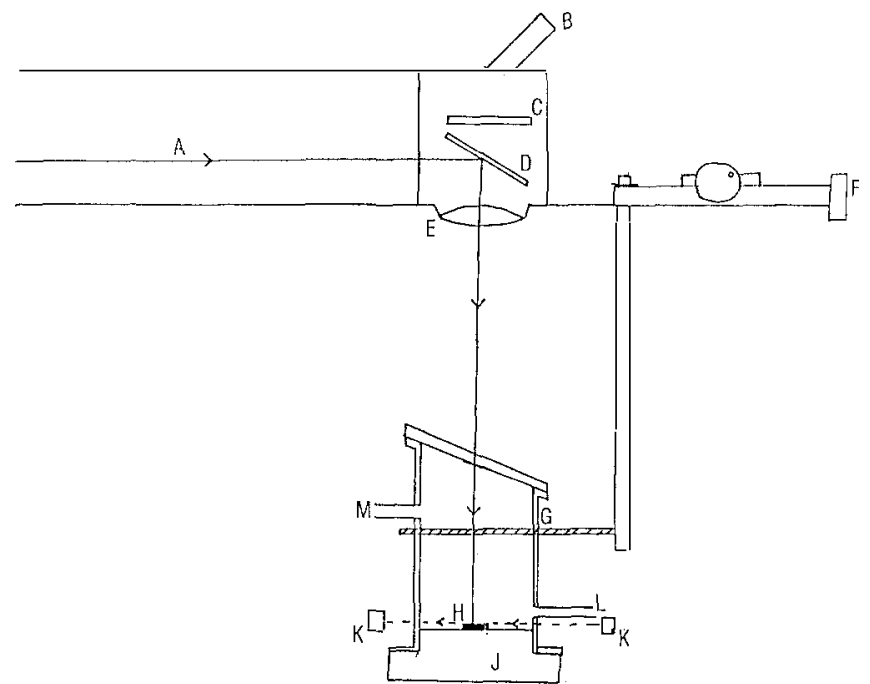

Fig. 1. Schematic diagram of the sample cell assembly used with the laser ablation system. $A$ Laser beam direction; $B$ binocular viewing head; $C$ viewing filter; $D$ steering mirror mount; $E$ objectiv lens (focal length $=150 \mathrm{~mm}$ ) $F \mathrm{X}-\mathrm{Y}-\mathrm{Z}$ directional sampling head; $G$ sample cell and holder; $H$ sample; $J$ PTFE base; $K$ IR beam and detector; $L$ argon inlet; $M$ argon outlet to ICP

gether with a Scott-type spray chamber. The slurries were pumped at a rate of $1 \mathrm{ml} \mathrm{min}^{-1}$ using a peristaltic pump (Gilson Minipuls 2, Anachem, Luton, Bedfordshire). Particle size measurements were made using a Coulter Counter ZM (Coulter Electronics Ltd., Luton).

ICP Instrumentation. The ICP-OES analysis was carried out using an ARL 3560 (Applied Research Laboratories, Crawley, Sussex, UK) simultaneous multichannel polychromator system. It had a holographic grating with 1080 lines per $\mathrm{mm}$ and was powered by a $27.12 \mathrm{MHz} \mathrm{RF}$ generator. It was fitted with a Fassel design torch and the observation height was $15 \mathrm{~mm}$ above the load coil.

The ICP-MS used was a VG PlasmaQuad ICP-MS. It was used in the scanning mode to produce a full mass scan of all the elements present in the geochemical samples.

Sample Preparation. The geochemical samples used in this work were South African Reference Materials (SARM) 2 (syenite), 4 (norite) and 5 (pyroxenite). They were all certified for a range of major, minor and trace elements.

The samples for laser ablation were prepared as pellets by mixing the powdered rocks with a binding agent and then pressing in a die. Several binding materials were considered including cellulose, methyl methacrylate and polyvinylalcohol. Polyvinylalcohol was selected as the most suitable. It was prepared as a $1 \%$ solution and typically $1-2 \mathrm{ml}$ of this was mixed with $1 \mathrm{~g}$ of sample. The rock and binder mixture was dried in a desiccator or in an oven at $50^{\circ} \mathrm{C}$ and then pressed in a $1.5 \mathrm{~cm}$ die at 10 tons pressure. Yttrium and indium were added as internal standards at $100 \mu^{\mathrm{g} \mathrm{g}^{-1}}$ levels. They were added as solutions together with the binding material.

The slurries were prepared by placing $0.5 \mathrm{~g}$ sample, $5 \mathrm{ml}$ of $0.1 \% \mathrm{Na}_{4} \mathrm{P}_{2} \mathrm{O}_{7}(\mathrm{BDH}$, Poole, Dorset, $\mathrm{UK})$ as a dispersing agent and $5 \mathrm{~g}(2.5 \mathrm{~mm}$ diameter) zirconia/silica beads (Glen Creston, Stanmore, Middlesex) into a plastic bottle [17] and 
Table 1. Instrument conditions used with laser ablation system

\begin{tabular}{ll}
\hline Connection tube length & $200 \mathrm{~cm}$ \\
Connection tube internal diameter & $7 \mathrm{~mm}$ \\
Laser energy & $2 \mathrm{~J} \mathrm{per} \mathrm{shot}$ \\
ARL 3560 ICP-OES & $1100 \mathrm{~W}$ \\
Forward power & $0.81 \mathrm{~min}^{-1}$ \\
Carrier gas flow rate & $121 \mathrm{~min}^{-1}$ \\
Coolant flow rate & $0.81 \mathrm{~min}^{-1}$ \\
Plasma gas flow rate & $25 \mathrm{~s}$ \\
Integration time per laser shot & $15 \mathrm{~mm} \mathrm{above} \mathrm{load}$ \\
Observation height & coil \\
& \\
VG PlasmaQuad ICP-MS & $1300 \mathrm{~W}^{-1}$ \\
Forward power & $0.81 \mathrm{~min}^{-1}$ \\
Carrier gas flow rate & $0.21 \mathrm{~min}^{-1}$ \\
Plasma gas flow rate & $131 \mathrm{~min}^{-1}$ \\
Coolant gas flow rate & \\
For full mass scan & \\
Dwell time $=250 \mu \mathrm{S}$ & \\
Number of scans $=120$ & \\
\hline
\end{tabular}

shaking for about 16 h overnight using a Pilamec Megapot Vibration Pot Mill (Pilamec, Lydney). The slurry was washed off the beads and then made up to $100 \mathrm{ml}$ with $0.1 \%$ $\mathrm{Na}_{4} \mathrm{P}_{2} \mathrm{O}_{7}$. Further dilutions were made for the analysis of the major elements.

\section{Procedures}

Studies were made of a number of parameters which affected the performance of both sample introduction systems. The operating conditions used are listed in Tables 1 and 2. A different laser ablation procedure was used for ICP-OES than for ICP-MS. For ICP-OES, a single pulse was used to ablate material, which was transported to the source in the carrier gas stream, and the optical emission measured. A full mass scan was obtained by ICP-MS by firing the laser repeatedly at 1.4 pulses per second for one minute, and the quadrupole mass spectrometer scanned continuously. Other laser ablation ICP-MS work [25] has shown that the number of pulses could probably be reduced. It was found that compared with the emission work, a lower plasma gas flow rate was required to obtain maximum response.

\section{Results and discussion}

\section{ICP-OES Measurements}

A range of major and minor elements were determined in SARM 5 using both slurry nebulisation and laser ablation sample introduction methods.

The laser ablation ICP-OES results are shown in Table 3. SARM 2 and SARM 4 were used for calibration using the internal standards, yttrium and indium to correct for any inter-sample ablation effects. It should be borne in mind that the results are obtained by calibration with a blank and single standard, a procedure which only merits the description of semi-quantitative. The agreement for the trace elements is excellent (the range for the certificate values is approximately $\pm 10 \%$ ). The results illustrate the importance of using closely matrix-matched standards. SARM 4 and SARM 5 are of similar elemental composition (Table 4) and
Table 2. Instrument conditions used with slurry nebulisation

\begin{tabular}{ll}
\hline ARL 3560 ICP-OES & \\
Forward power & $1100 \mathrm{~W}$ \\
Carrier gas flow rate & $0.81 \mathrm{~min}^{-1}$ \\
Coolant flow rate & $121 \mathrm{~min}^{-1}$ \\
Plasma gas flow rate & $0.81 \mathrm{~min}^{-1}$ \\
Observation height & $15 \mathrm{~mm} \mathrm{above} \mathrm{load} \mathrm{coil}$ \\
Sample flow rate & $1 \mathrm{ml} \mathrm{min}-1$ \\
Pre-integration time & $20 \mathrm{~s}$ \\
Integration time & $10 \mathrm{~s}$
\end{tabular}

Table 3. Laser ablation ICP-OES analysis of SARM 5

\begin{tabular}{lccc}
\hline Element & \multicolumn{2}{l}{ Measured concentration } & \\
\cline { 3 - 4 } & $\begin{array}{l}\text { Calibrated with } \\
\text { SARM 2 }\end{array}$ & $\begin{array}{l}\text { Calibrated with } \\
\text { SARM 4 }\end{array}$ & $\begin{array}{l}\text { Certificate }_{\text {value }^{\mathrm{a}}} \\
\text { SA }\end{array}$ \\
\hline $\mathrm{Al}$ & $3.80(0.47)$ & $2.30(0.28)$ & \\
$\mathrm{K}$ & $0.30(0.01)$ & $0.14(0.006)$ & 0.2 \\
$\mathrm{Na}$ & $0.23(0.02)$ & $0.33(0.03)$ & 0.27 \\
$\mathrm{Si}$ & $36.0(1.4)$ & $21.0(0.82)$ & 24.0 \\
$\mu \mathrm{g} \mathrm{g}-1$ & & & 46 \\
$\mathrm{Ba}$ & $88.0(7.20)$ & $59(4.8)$ & 1700 \\
$\mathrm{Mn}$ & $820(14.0)$ & $1710(29)$ & 32 \\
$\mathrm{Sr}$ & $22(3.1)$ & $27.0(3.6)$ & 1200 \\
$\mathrm{Ti}$ & $870(87)$ & $1090(110)$ & \\
\hline
\end{tabular}

Standard deviations in parentheses

Number of replicates $=4$

a Certificate of analysis, NIM-P, Pyroxenite SARM 5, SA Bureau of Standards, Pretoria, RSA

Table 4. Certificate concentrations for SARMs used for geochemical analysis

\begin{tabular}{|c|c|c|c|}
\hline \multirow[t]{2}{*}{ Constituent } & \multicolumn{3}{|c|}{ Certified-value $^{a}$} \\
\hline & SARM 2 & SARM 4 & SARM 5 \\
\hline $\mathrm{SiO}_{2} / \%$ & 63.63 & 52.64 & 51.10 \\
\hline $\mathrm{Al}_{2} \mathrm{O}_{3} / \%$ & 17.34 & 16.50 & 4.18 \\
\hline $\mathrm{Na}_{2} \mathrm{O} / \%$ & 0.43 & 2.46 & 0.37 \\
\hline $\mathrm{K}_{2} \mathrm{O} / \%$ & 15.35 & 0.25 & 0.09 \\
\hline \multicolumn{4}{|l|}{ Total Fe as } \\
\hline $\mathrm{Fe}_{2} \mathrm{O}_{3} / \%$ & 1.40 & 8.97 & 12.70 \\
\hline $\mathrm{MnO}$ & $80 \mu \mathrm{g} \mathrm{g}^{-1 \mathrm{~b}}$ & $0.18 \%$ & $0.22 \%$ \\
\hline $\mathrm{TiO}_{2}$ & $265 \mu \mathrm{g} \mathrm{g}^{-1 b}$ & $0.20 \%$ & $0.20 \%$ \\
\hline $\mathrm{BaO}$ & $0.27 \%$ & $102 \mu \mathrm{g} \mathrm{g}^{-1 \mathrm{~b}}$ & $46 \mu \mathrm{g} \mathrm{g}^{-1 \mathrm{~b}, \mathrm{c}}$ \\
\hline $\mathrm{Co} / \mu \mathrm{g} \mathrm{g}^{-1}$ & $3^{\mathrm{c}}$ & 58 & 110 \\
\hline $\mathrm{V} / \mu \mathrm{g} \mathrm{g}^{-1}$ & 10 & 220 & 230 \\
\hline $\mathrm{Zn} / \mu \mathrm{g} \mathrm{g}^{-1}$ & $10^{\mathrm{c}}$ & 68 & 100 \\
\hline
\end{tabular}

a Certificates of analysis, SA Bureau of Standards, Pretoria, RSA. Uncertainties are not listed for these elements

b Concentration of element, not oxide

c Uncertified values from certificate of analysis

the results obtained reflect this. SARM 2 contains a high concentration of potassium compared to the other two standards. As this is the most obvious difference between the sample matrices one possible explanation for these observations is that they could be related to the presence of easily 
Table 5. Slurry nebulisation ICP-OES analysis of SARM 5

\begin{tabular}{lcc}
\hline Element & $\begin{array}{l}\text { Measured } \\
\text { concentration }\end{array}$ & Certificate value \\
\hline$\%$ & & \\
$\mathrm{Al}$ & 1.2 & 2.2 \\
$\mathrm{Ca}$ & 0.9 & 1.9 \\
$\mathrm{~K}$ & 0.09 & 0.07 \\
$\mathrm{Mg}$ & 6.5 & 15.3 \\
$\mathrm{Si}$ & 13.2 & 23.9 \\
$\mu \mathrm{g} \mathrm{g}{ }^{-1}$ & & \\
$\mathrm{Cu}$ & 17 & 18 \\
$\mathrm{Mn}$ & 920 & 1703 \\
$\mathrm{Sr}$ & 22 & 32 \\
$\mathrm{Ti}$ & 410 & 1199 \\
\hline
\end{tabular}

Number of replicates $=3$

Table 6. Slurry nebulisation ICP-OES analysis of SARM 5 with acid

\begin{tabular}{lcc} 
Element & Measured concentration & $\begin{array}{c}\text { Certificate } \\
\text { value }\end{array}$ \\
\hline$\%$ & $1.5(0.02)$ & 2.2 \\
$\mathrm{Al}$ & $1.0(0.01)$ & 1.9 \\
$\mathrm{Ca}$ & $0.08(0.003)$ & 0.07 \\
$\mathrm{~K}$ & $8.4(0.08)$ & 15.3 \\
$\mathrm{Mg}$ & $16.3(0.1)$ & 23.9 \\
$\mathrm{Si}$ & & \\
$\mu \mathrm{g} \mathrm{g}{ }^{-1}$ & $19(0.2)$ & 1703 \\
$\mathrm{Cu}$ & $1128(23)$ & 32 \\
$\mathrm{Mn}$ & $24(0.1)$ & 1199 \\
$\mathrm{Sr}$ & $490(8)$ & \\
$\mathrm{Ti}$ & &
\end{tabular}

Standard deviations in parenthesis

Number of replicates $=3$

Table 7. Extraction into solution by acid

\begin{tabular}{ll}
\hline Element & $\begin{array}{l}\text { Fraction of concentration in } \\
\text { slurried material found in solution } \\
\text { after addition of acid }\end{array}$ \\
\hline $\mathrm{Al}$ & 0.042 \\
$\mathrm{Ca}$ & 0.003 \\
$\mathrm{Fe}$ & 0.04 \\
$\mathrm{~K}$ & 0.81 \\
$\mathrm{Mg}$ & 0.044 \\
$\mathrm{Sr}$ & 0.75 \\
$\mathrm{Cu}$ & 0.88 \\
$\mathrm{Mn}$ & 0.062 \\
$\mathrm{Ti}$ & 0.08 \\
$\mathrm{Si}$ & 0.025 \\
\hline
\end{tabular}

ionisable elements. At present, experimental work is being carried out to determine whether the ablated material reaching the plasma is representative of the whole sample.

The results from the slurry nebulisation introduction into the ICP-OES are given in Table 5. Calibration was carried out using standard solutions prepared by diluting $1000 \mu \mathrm{g} \mathrm{ml}{ }^{-1}$ stock solutions (BDH Chemicals, Poole, Dorset). Although the measured concentrations are in poor agreement with the certificate values, they all indicate the correct order of magnitude for the elements shown and

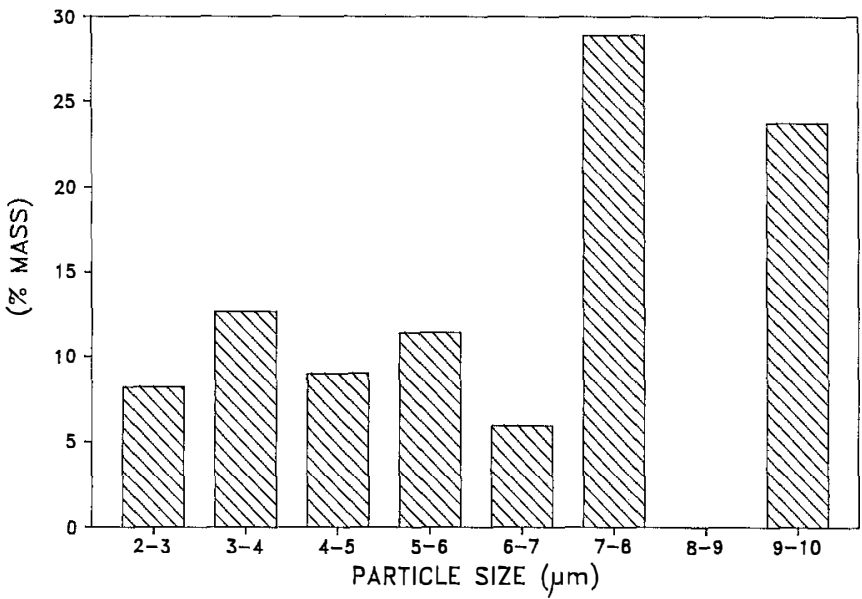

Fig. 2. Particle size distribution for SARM 5 slurry

compare very favourably with the results of Ebdon et al. [23] discussed earlier for the analysis of coal by ICP-MS. These discrepancies can possibly be explained by looking at the particle size distribution for SARM 5 (Fig. 2). The role of particle size was discussed by Halicz and Brenner [20] who found that it was not possible to get satisfactory results for the analysis of silicate rock slurries even though electron micrograph studies showed the particle size to be less than $2 \mu \mathrm{m}$. They did, however, obtain good results for the analysis of clay minerals for which the particle size was substantially less than $2 \mu \mathrm{m}$. Other workers, notably Ebdon and coworkers $[16,17]$ have demonstrated the importance of particle size. As a high proportion of the particles of SARM 5 were in the range $7-10 \mu \mathrm{m}$, it is thought that reduction of the particle size could improve the ICP-OES results for slurry nebulisation of geochemical samples.

A method of reducing particle size of the material in the slurry using acid during the grinding stage was investigated. $2.5 \mathrm{ml}$ of dispersing agent was replaced by $2.5 \mathrm{ml}$ concentrated nitric acid (Fisons, Loughborough). The results obtained are given in Table 6 . They show improved agreement between measured and certificate values compared with Table 5. The slurry was filtered through a $0.45 \mu \mathrm{m}$ pore filter and this solution was analysed by ICP-OES. Table 7 shows the $\%$ of the total concentration of the elements present in the slurried sample found in the solution after addition of acid. This shows that almost all the $\mathrm{K}, \mathrm{Sr}$ and $\mathrm{Cu}$ had been extracted by the acid into solution. This is the reason for the improved results for these three elements. The other elements for which results have been reported have less than $10 \%$ of their concentration in solution. The improvement in the measured concentration could be attributed to improved grinding with the addition of acid.

\section{Laser ablation ICP-MS measurements}

As ICP-MS would only be used when the levels of the determinands were such that the extra detection power of the mass spectrometer was required, results are only of interest for the trace rare earth elements in samples of this type. A laser ablation ICP-MS scan across the mass range encompassing the rare earth elements is illustrated in Fig. 3. The major isotope peaks are labelled. It shows that all the 


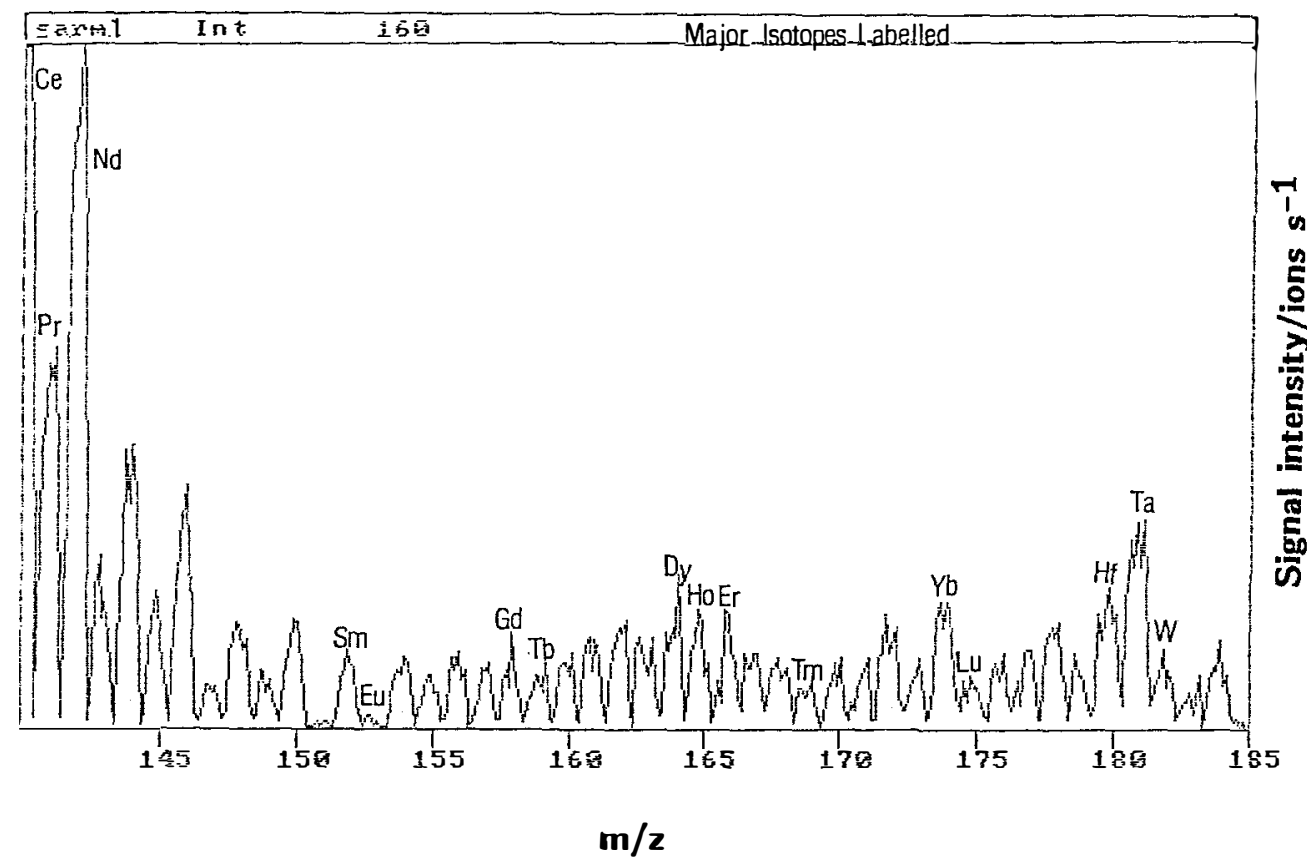

Fig. 3

ICP-MS scan of the rare earth elements in SARM 1

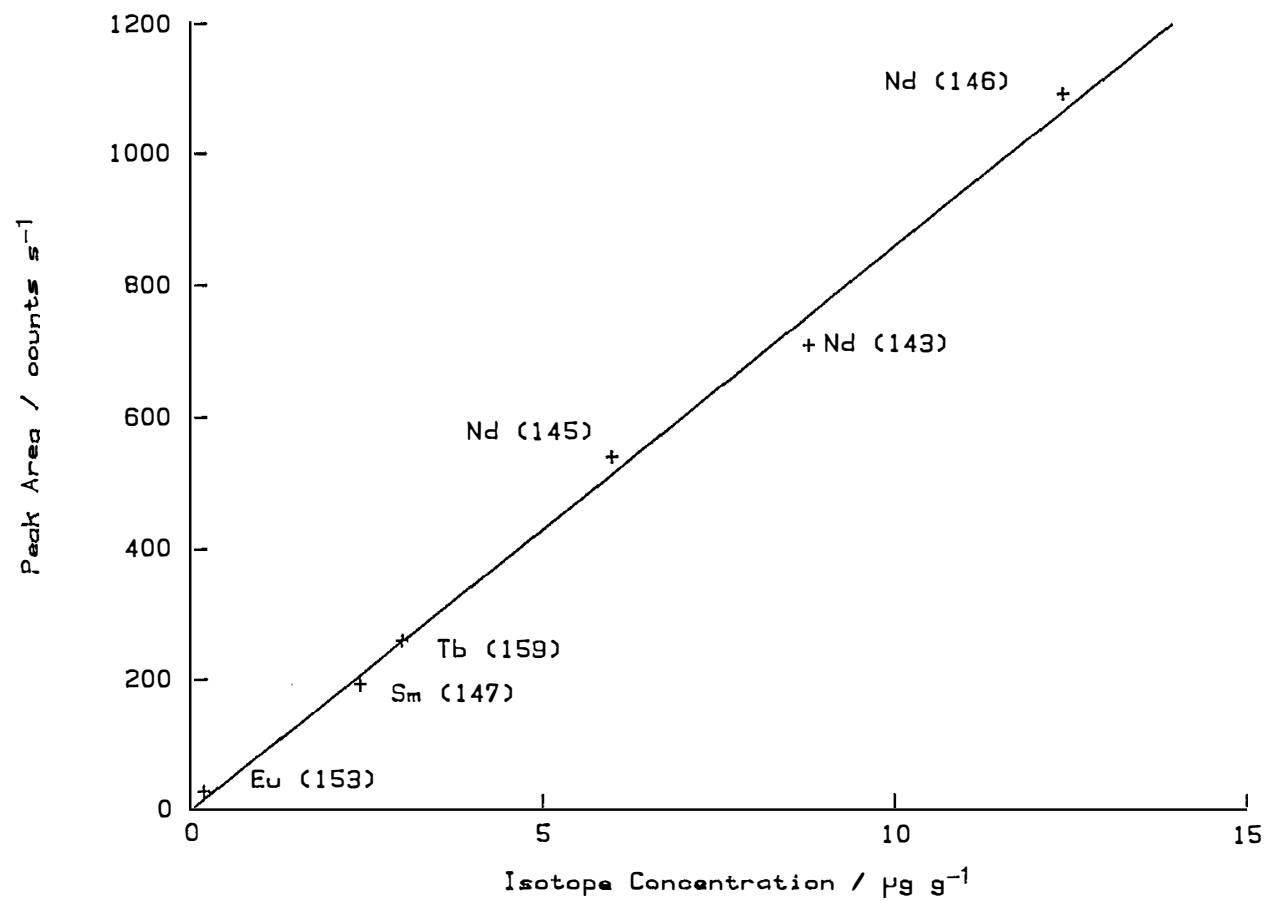

Fig. 4

Plot of peak area vs. isotope concentration for the rare earth elements in SARM 1 (only certified elements included)

rare earth elements present in SARM 1 can be detected by laser ablation ICP-MS using this system. Europium is at a concentration of $0.35 \mu \mathrm{g} \mathrm{g}^{-1}$ and has isotopes at $\mathrm{m} / \mathrm{z}=153$ (relative abundance $=52.2 \%$ ) and $\mathrm{m} / \mathrm{z}=151$ (relative abundance $=47.8 \%$ ). Both of these isotopes can be seen clearly on the scan suggesting that a limit of detection of about $0.1 \mu \mathrm{g} \mathrm{g}^{-1}$ is possible for europium using this laser ablation ICP-MS system.

A plot of peak area vs isotope concentration reveals a linear relationship for the rare earth elements in SARM 1 (Fig. 4). It is sufficiently linear for any one isotope to be used as an internal standard for the others.

\section{Conclusions}

The laser ablation system constructed can be used for solid sample introduction into ICP-OES and ICP-MS to make qualitative and some quantitative determinations of the elemental composition of geochemical samples.

For ICP-OES, matrix effects are present which require standardisation to be made with closely matched materials. As there is a limited availability of such standard materials, this requirement means that the procedure will be only semiquantitative. It is possible, from the results obtained in this work, that the matrix effects could be related to the presence 
of easily ionisable elements. For the ICP-MS work, the variation in sensitivity obtained for the rare earth elements is sufficiently small to allow internal standardisation using one element to correct for sensitivity variations in the others and detection to $\mu \mathrm{g} \mathrm{g}^{-1}$ levels is possible for these types of materials.

The results obtained by slurry nebulisation ICP-OES reported in this work indicate that particle size of the suspended material must be reduced to less than $8 \mu \mathrm{m}$ if standard solutions are to be used for calibration purposes. The addition of acid, used to assist in the grinding process, resulted in improved agreement between measured and certificate values.

Further studies of the laser ablation technique are in progress including alternative sample preparation methods to reduce intersample matrix effects.

Acknowledgements. This work was supported by the Underlying Research Programme of the UKAEA.

\section{References}

1. Darke SA, Long SE, Tyson JF (1987) UK At Energy Res Estab [Rep] AERE R-12821

2. Zil'bershtein Kh I (1985) ICP Inf Newsl 10:964-976

3. Abercrombie FN, Silvester MD, Murry AD, Barringer AR (1978) Applications of inductively coupled plasmas to emission spectroscopy, eastern analytical symposium. Franklin Institute Press, Philadelphia, USA, pp 121-145

4. Kawaguchi J, Xiu J, Tanaka T, Muzuike A (1982) Bunseki Kagaku 31 : E185 - E191

5. Hale M, Thompson M (1983) Trans Inst Min Metall Sect B $92: 23-27$
6. VG Isotopes Ltd. Elemental Division (1987) Technical Information PQ7094A

7. Dittrich K, Niebergall K, Wennrich R (1987) Fresenius' Z Anal Chem 328:330-337

8. Carr JW, Horlick G (1982) Spectrochim Acta Part B 37:1-15

9. Ishizuka T, Uwamino Y (1983) Spectrochim Acta Part B $38: 519-527$

10. Thompson M, Goulter JE, Sieper F (1981) Analyst 106:3239

11. Arrowsmith P (1987) Anal Chem 59:1437-1444

12. Gray AL (1985) Analyst 110:551 - 556

13. Babington RS, US Patent 3421692

14. Ebdon L, Cave MR (1982) Analyst 107:172-178

15. Ripson PAM, de Galan L (1981) Spectrochim Acta Part B $36: 71-76$

16. Ebdon L, Collier AR (1988) Spectrochim Acta Part B 43:355369

17. Sparkes ST, Ebdon L (1986) Anal Proc 23:410-412

18. Sugimae A, Mizoguchi T (1982) Anal Chim Acta 144:205212

19. Spiers GA, Dudas MJ, Hodgins LW (1983) Clays Clay Miner $31: 397-400$

20. Halicz L, Brenner IB (1987) Spectrochim Acta Part B 42:207217

21. Dick WA, Page JR, Jewell KE (1985) Soil Sci 139:211-218

22. Williams JG, Gray AL, Norman P, Ebdon L (1987) J Anal At Spectrom 2:469-472

23. Ebdon L, Foulkes ME, Parry HGM, Tye CT (1988) J Anal At Spectrom 3:753-761

24. Sneddon J (1986) Spectroscopy 1:34-41

25. Tye C, Gordon J, Webb P (1987) International Laboratory. December: $35-41$

Received July 3, 1989 